\title{
Conservation status and threats for African reptiles
}

Krystal A. Tolley, Graham J. Alexander, William R. Branch, Philip Bowles and Bryan Maritz

\begin{abstract}
The assimilation of information on taxonomy, distribution, basic ecology and conservation status of Africa's reptiles lags far behind that for most other continents. Many regions of mainland Africa are rarely surveyed, resulting in severe knowledge gaps that currently limit effective conservation of African reptiles. Here, we provide a précis on the knowledge gaps and conservation status of mainland African reptiles, and quantify the main threats based on IUCN Red List of Threatened Species assessments using publicly available distribution data. Our results show that these data are insufficient to confidently identify areas of high biodiversity, with large gaps in knowledge in the Horn of Africa, central Africa and West Africa. There is a strong overall taxonomic bias in extinction risk with $45 \%$ of families more threatened than expected by chance. Furthermore, Amphisbaenidae, Chameleonidae, Gerrhosauridae, Testudinidae, Viperidae all have a high percentage of their constituent species at risk. Overall, land transformation for agriculture, particularly subsistence farming, constitutes the primary threat to African reptiles, and our derived Threat Index based on socioeconomic traits of African countries show that risk is high in Burundi, Ethiopia, Liberia, Malawi, Rwanda and Sierra Leone. These findings highlight important challenges facing the conservation of African reptiles, and we suggest that conservation priorities in mainland Africa be focussed on areas where the potential for overall loss of biodiversity is high, particularly in regions where knowledge is inadequate.
\end{abstract}

\section{Introduction}

Africa is a mega-continent with a land surface larger than China, India, North America and Western Europe combined. Its size and geographic position allows for considerable diversity of habitats ranging from true desert to impenetrable tropical rainforest. Nine of the world's 34 biodiversity hotspots are in Africa (Mittermeier et al., 2004). It is the only continent with an essentially intact, albeit heavily threatened, megafauna and it has a rich evolutionary history. Despite its historical, biological and economic significance, its biodiversity remains poorly known, particularly in comparison to temperate regions of the world (Deikumah et al., 2014). 
Mainland Africa (i.e. excluding Madagascar and oceanic islands) is home to at least 1648 reptile species, which together with 378 endemic species known from the island of Madagascar, total $\sim 20 \%$ of the world's reptiles (Uetz and Hošek, 2015). The species count in Africa continues to rise steadily, and the rate of discovery over recent decades shows no sign of abating (Fig. 1). Remarkably, this rapid rate of discovery is based on relatively scant survey coverage (Fig. 1). While Madagascar is well known for its mega-diversity, mainland Africa also hosts a substantial reptile fauna, particularly in the montane tropical Eastern Arc Mountains, Albertine Rift, Cameroon Highlands, and arid southern Africa (Böhm et al., 2013; Lewin et al., in review).

Despite having a large proportion of the world's reptiles, Africa's fauna is poorly documented in terms of distribution and taxonomy, especially in tropical Central Africa, the Sahel, the Horn of Africa (Böhm et al., 2013) and Afrotropical forests (Deikumah et al., 2014), although this many not hold for other areas of research, e.g. reptile community ecology (Luiselli, 2008). Southern Africa and East Africa are comparatively well explored, but even within these regions significant gaps remain. Of the nearly 2.5 million reptile records ( $\mathrm{N} 9400$ species) in the Global Biodiversity Information Facility (GBIF), only 104,000 are from Africa. When compared to other mega-diverse reptile faunas, Africa is obviously sparsely sampled and understudied. For example, publicly accessible databases show that Mexico has $\sim 380$, ooo records covering $\sim 800$ squamate reptiles (at an average of 475 records per species), while Australia has $\sim 700$,000 covering $\sim 900$ species (Chapman, 2009; Wilson et al., 2013) averaging nearly 780 records per species. 


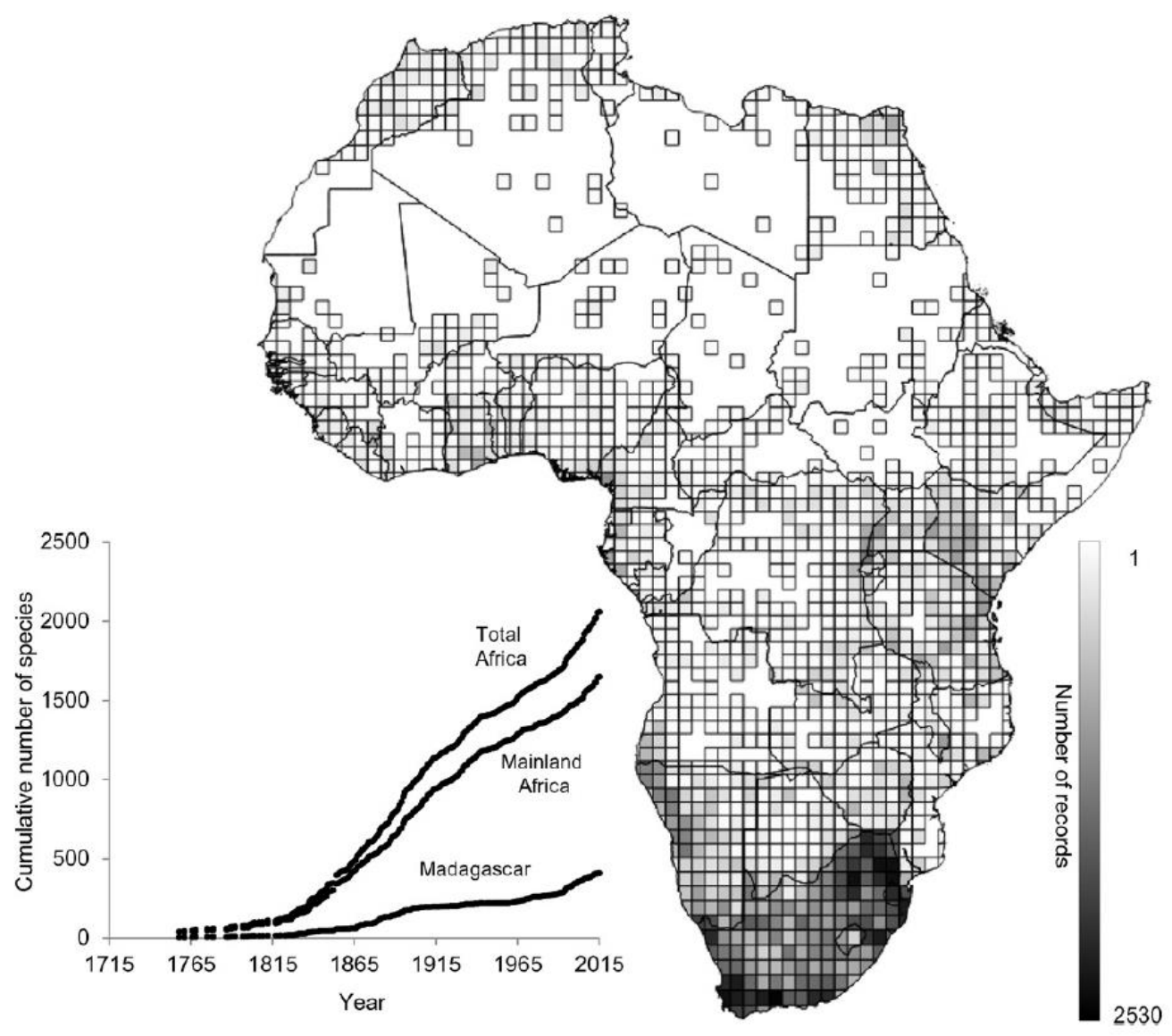

Fig. 1. Distribution of ca. 84,000 records available from publicly accessible databases (see Materials and methods) for reptiles from mainland Africa, with the cumulative number of described species of reptiles from mainland Africa, Madagascar, and combined, since 1750 (inset).

Conversely, the coverage in Africa averages just over 60 records per species. This dearth of knowledge increases the risk to the long-term sustainability of African biodiversity and undetected extinctions, and is likely to result in misdirected conservation priorities at country and local levels (e.g. Pimm et al., 2014; Jenkins et al., 2013, 2015). Prioritisation exercises are often aimed at protection of habitat in regions with high species richness because this strategy results in the 'biggest bang for buck' by protecting the greatest number of species (e.g. Fleishman et al., 2006; Murdoch et al., 2007; Myers et al., 2000; Scott et al., 1987). Species richness is also a valuable metric because it is a proxy for other important dimensions of biodiversity, such as phylogenetic diversity and ecosystem functioning (Chiarucci et al., 2011; Davies and Buckley, 2011; Forest et al., 2007; Maritz et al., 2016-in this issue; Petchey and Gaston, 2002). However, it is likely that inference of richness patterns from the present knowledge-base is biased by regional difference in sampling effort (e.g. Engemann et al., 2015).

The lack of baseline data for Africa is compounded by a comparatively low proportion of published IUCN extinction risk assessments for the continent (IUCN, 2015; Meiri and Chapple, 2016-in this issue). A recent ongoing global initiative to assess all reptiles (IUCN Global Reptile Assessment, GRA) has substantially increased the number of species assessed (IUCN, 2015). For example, all reptiles in Meso- 
America, North America and Europe have been assessed in the last decade, as have all snakes in Southeast Asia. Despite the GRA initiative, only $\sim 50 \%$ of the described reptiles in mainland Africa currently have published assessments, and $15 \%$ of these are classified as Data Deficient (Bates et al., 2014; IUCN, 2015). This is in stark contrast to Madagascar for which all but recently described species have been assessed (Jenkins et al., 2014), although the percentage of Data Deficient species is high for Madagascar (Bland and Böhm, 2016-in this issue).

In this study, we investigated the patterns of diversity, conservation status and threats of mainland African reptiles using existing publicly available datasets. Quantification of biodiversity (in its simplest metric, species richness) increasingly relies on "Big Data" meta-analyses using publicly available databases (e.g. Böhm et al., 2013; Engemann et al., 2015). Given that many species are habitat specialists, have small distributions and are sensitive to habit transformation (Jenkins et al., 2014), we used existing IUCN conservation assessments for African reptiles to investigate the underlying threats that trigger the IUCN threat status under Criterion B (reduction in extent and quality of habitat). We therefore expected extinction risk status to be taxonomically biased, with a higher proportion of Threatened species in families with habitat specialists. We then quantified the emerging patterns in threat categories for these species. We also identified regions with the highest risk of biodiversity loss by creating a Threat Index based on socioeconomic traits (e.g. Polasky, 2008), because we expected that fast-emerging economies with high human population growth would be under the most pressure for land utilisation. Finally, we provide some guidance for prioritising work, particularly in terms of data that have been collected, but is not available in publicly accessible databases.

\section{Materials and methods}

Point locality data for reptiles from mainland Africa were accessioned from the publicly accessible online data sources GBIF, Herpnet, and downloadable records from the Natural History Museum, London. To this, we added records from comprehensive compilations with locality data: Baha El Din (2006) for Egypt, and the regional atlas project for South Africa, Swaziland and Lesotho available online from the Animal Demography Unit (Bates et al., 2014). These data sources represent the majority of publicly available data sources of distribution records for Africa. We relied on these sources of "Big Data" because such information is increasingly targeted for large scale spatial analyses of biodiversity patterns. Data were screened for errors and spatial outliers, duplicates were removed and taxonomy was updated following Uetz and Hošek (2015). Records that included only descriptions of localities were georeferenced using Google Earth. Because none of our data sources had incorporated the recent division between South Sudan and Sudan, 'Sudan' in our analysis refers to the pre-2012 borders. To examine the location and extent of sampling gaps, we calculated sampling density as the number of records in each one-degree grid across mainland Africa and 
mapped this metric using QGIS v.2.81. We also calculated country-level sampling effort as the total number of records per $\mathrm{km}^{2}$.

We estimated species richness using two methods: firstly for one-degree grid cells for point locality data (WGS84) using Biodiverse v1.o (Laffan et al., 2010), and general linear regression was used to test the hypothesis that estimated species richness is an artefact of sample density. Secondly, we estimated country-level species richness in two ways and compared them. The first was on the basis of the accumulated public data, and second, on the basis of the text descriptions of geographic range included for each mainland species in the Reptile Database (Uetz and Hošek, 2015). These descriptions are based on synthesised literature rather than spatially explicit data only, and although imperfect, could provide a more complete country-level species richness estimate than available point locality data. We compared these two datasets using simple linear regression to highlight countries that are underrepresented in our accumulated database.

To assess the magnitude of country-level sampling, we selected the 15 best sampled countries on mainland Africa (Swaziland, South Africa, Lesotho, Namibia, Rwanda, Kenya, Uganda, Tanzania, Ghana, Malawi, Equatorial Guinea, Zimbabwe, Gabon, Burundi, and Togo) on the basis of sample density. For these 15 countries we used multiple stepwise regression analysis to assess the effects of mean annual temperature and mean annual precipitation (Bioclim.org), as well as mean latitude, elevational range, and country area on country-level species richness estimated from text descriptions presented in Uetz and Hošek (2015). The regression procedure identified country area as the foremost determinant of country-level species richness. We then used this species-area model coefficient to estimate the predicted species richness for all African countries, and compared these estimates to our measures of species richness based on our point locality database.

The IUCN Red List of Threatened Species was queried for threat status and criteria for all species-level global assessments completed by November 2014, including the published Red List for South Africa, Swaziland and Lesotho (Bates et al., 2014), which supersedes the older IUCN assessments online. The Red List statistics were interrogated to calculate the percentage of species in each category (Critically Endangered-CR; Endangered-EN; Vulnerable-VU; Near ThreatenedNT; Least Concern-LC; Data Deficient-DD; Not Evaluated-NE). In addition, the underlying threats were quantified from the published assessments to ascertain which threats constituted the greatest risk to mainland African reptiles. Threats were broadly categorised as:

- Agriculture - including commercial and non-commercial livestock, crops, and timber production 
- Resource abstraction - including informal and formal timber harvesting and subsistence hunting and gathering

- Urbanisation - including development of associated infrastructure

- Changes in fire regime

- Mining

- Alien vegetation infestation

- Climate change

- Pollution.

The extinction risk within each family was assessed by estimating the proportion of species classified as Threatened (Propthreat). As the true threat status of DD species is uncertain (Böhm et al., 2013; Hoffmann et al., 2010), we divided them into Threatened categories in the same proportions as the EX, CR, EN and VU species: (Propthreat) $=(\mathrm{CR}+\mathrm{EN}+\mathrm{VU}) /(\mathrm{N}-\mathrm{DD})$. Upper and lower bounds for this index were estimated following (Böhm et al., 2013): [lower bound (Propthreat) $=(\mathrm{CR}+\mathrm{EN}+\mathrm{VU}) / \mathrm{N}$ ], and [upper bound $($ Propthreat $)=(\mathrm{CR}+\mathrm{EN}+\mathrm{VU}+\mathrm{DD}) / \mathrm{N}]$, where $\mathrm{N}$ is the number of species assessed. This is a conservative approach as DD species are likely to be poorlyknown habitat specialists.

The proportion of Threatened species in each family was compared to an expected null distribution following Bielby et al. (2006) and Böhm et al. (2013) using R version 3.2.2 ( $\mathrm{R}$ Development Core Team, 2011). The null distribution was generated for 1000 unconstrained randomisations that assigned a threat status to each species based on the proportion of Threatened species in our sample and the number of species in each family. The number of observed Threatened species in each family was compared against the null distribution, rejecting the null hypothesis that extinction risk is randomly distributed if the value for a specific family fell outside 95\% (two-tailed) of the null distribution. Families with higher risk than expected by chance were determined by comparing the number of times the expected value from the null distribution was larger than the observed value. Finally, to examine whether the overall distribution of threat status was significantly different across families, a $\chi^{2}$ test was used to compare the observed and expected numbers of Threatened species in each family. Families with fewer than 22 species were omitted from analysis because statistical power required to detect the null hypothesis randomly distributed extinction risk was determined as insufficient using a binomial test.

In order to assess country-level threats to reptile diversity we developed and mapped a Threat Index across mainland Africa. We drew on several political and economic factors including per capita GDP, annual GDP growth percentage, population density, the percentage of land currently protected, as well as an index of overall governance. These data were retrieved from the World Bank database 
(www.worldbank.org), and averaged across the most recent five years for which data were available (typically 2008-2012). We also retrieved an index of climate change impact vulnerability for each country from the Centre for Global Development (www.cgdev.org). We reasoned that rates of habitat transformation were likely to be highest in countries with dense populations of poor citizens, that are poorly governed, with rapidly growing economies, limited protected areas, and that are vulnerable to climate change effects. For each variable we assigned each country an integer score (1-4) based on the quartile values of each variable, and calculated the Threat Index for each country as the normalised $(0-100)$ sum of scores for each variable.

\section{Results}

A total of 83,724 unique records (after filtering for duplicates, locality errors and missing point localities), covering 1349 of the 1648 reptile species known from mainland Africa were combined into our point locality database (Fig. 1). Thus, for 299 species (18\%), no specific locality data were found in the publicly accessible databases we queried. Sampling density ranged dramatically across the continent from zero records per cell across large parts of the Congo Basin, the Sahel, arid West Africa, and the Horn of Africa, to several hundred records (maximum 2530) per cell in parts of southern Africa (primarily South Africa and western Namibia) and East Africa (primarily Eastern Arc and Albertine Rift).

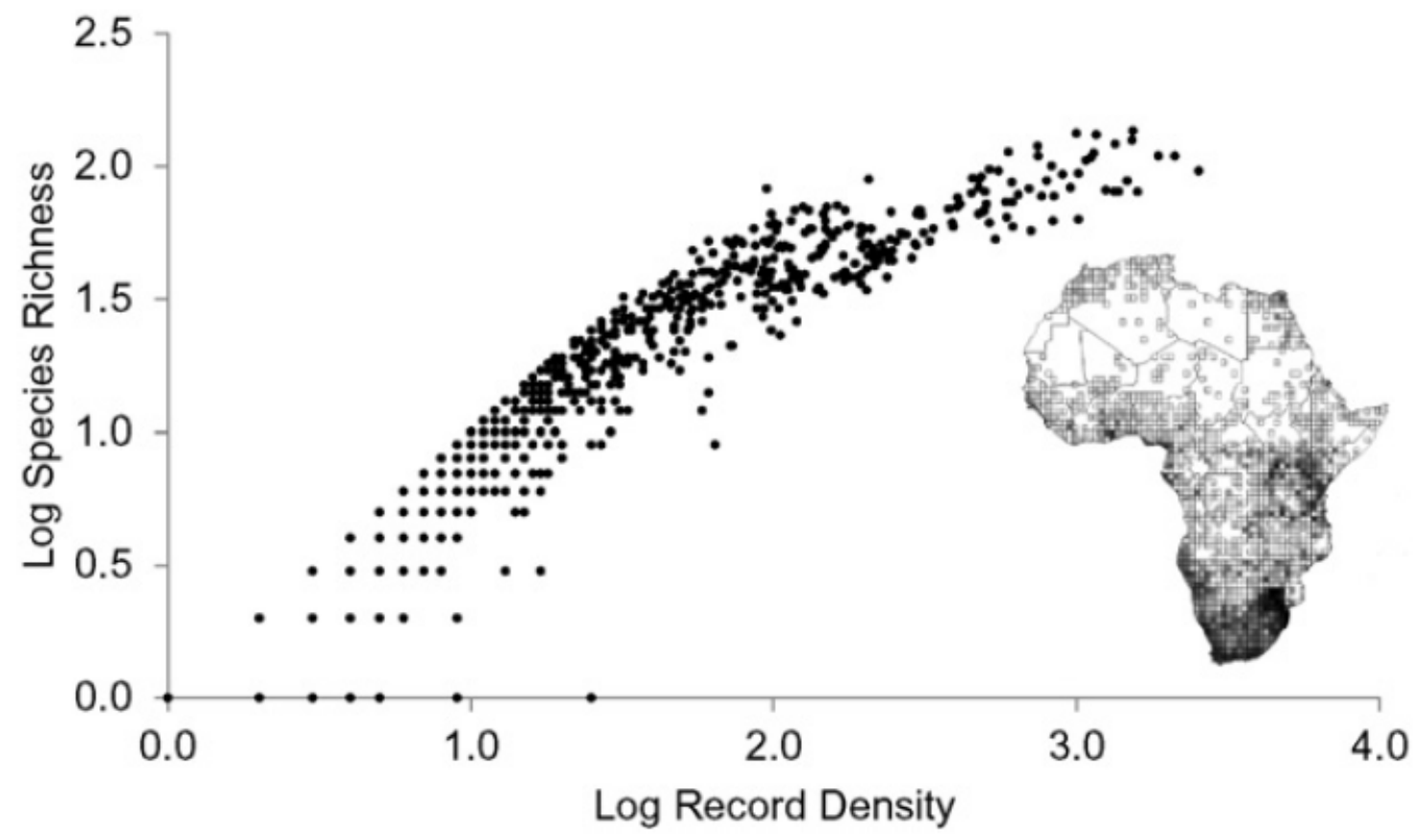

Fig. 2. The relationship between the number of records per grid cell (log Record Density) with species richness (log Species Richness). Inset: Species richness pattern in mainland Africa based on available records (dark areas indicate higher richness). 
Species richness was estimated across mainland Africa (Fig. 2), but the shortage of records produced unreliable species richness patterns as (log) sample density and estimated (log) species richness were strongly positively correlated ( $\mathrm{F}_{235}$ $=146.5 ; \mathrm{P} b 0.001 ; \mathrm{r}^{2}=0.97, \mathrm{~b}=0.046 ;$ Fig. 2 ), suggesting that species richness patterns based on point localities are biased by number of records available in each grid cell. The comparison between our accumulated database and Reptile Database (Uetz and Hošek, 2015) text descriptions of geographic range revealed that the accumulated database underestimated the species richness for most countries in comparison to estimates derived from the Reptile Database. In some instances, this effect was drastic with underestimation of more than 150 species below those of the Reptile Database.

Country-level species richness was strongly positively correlated with logtransformed area $\left(\mathrm{F}_{1,46}=94.87 ; \mathrm{P}\right.$ b 0.001; $\left.\mathrm{r}^{2}=0.68\right)$. Although the model slope (0.90 $\pm 0.10 ; 0.71-1.08$ mean $\pm \mathrm{SE}$; 95\% CI) was similar to 1 , the model intercept (mean $\pm \mathrm{SE}$; 95\% CI: $-50.02 \pm 15.80 ;-81.85--18.19$ ) suggests that our accumulated data set underestimated country-level species richness by between 20 and 80 (mean: 50) species (Fig. S1). The species-area function for the 15 best surveyed countries in mainland Africa was described by the function: species richness $=0.66 \times \mathrm{e}^{1,03}$ (Area) (Fig. 3). Relative to this function, our accumulated data demonstrated dramatic negative residuals suggesting chronic under-representation in publicly-accessible databases (Fig. 3).

Summary statistics of IUCN assessment categories show that the majority of species on mainland Africa have not been evaluated (NE) in stark contrast to Madagascar, which is very well known as a result of the IUCN Global Reptile Assessment initiative (Fig. S2, Table 1a). Mainland threat proportion is approximately $8 \%$, but could range from 7 to $14 \%$ due to the presence of $\mathrm{NE}$ species (Table 1a). From the mainland, only chameleons (Chamaeleonidae) have $\mathrm{N}$ 90\% of the species assessed, whereas on average most other groups have only half the species assessed (Fig. 4, Table 1b). In some families, none of the species have been globally assessed (Blanidae, Eublepharidae, Varanidae, Boidae, Natricidae, Pythonidae, Geoemydidae) although some have regional assessments (Bates et al., 2014). On average, snakes have proportionally the fewest assessed species (Table 1b). Of note is that two lizard species from mainland Africa (Tetradactylus eastwoodae, Scelotes guntheri) are considered Extinct (EX; Bates et al., 2014), both from South Africa.

Extinction risk, calculated as the threat proportion and corresponding measures of confidence estimated by family (Fig. 4) show that the most Threatened families are the Crocodylidae (66\%), Testudinidae (47\%), Gerrhosauridae (40\%), Amphisbaenidae (35\%), Chamaeleonidae (27\%), and Pelomedusidae (35\%). However, due to the large number of NE species, the threat level could likely 
be much higher for Typhlopidae (upper bound 59\%), Viperidae (upper bound 42\%), Leptotyphlopidae (upper bound 41\%), Sphaerodactylidae (upper bound $33 \%$ ), and Scincidae (upper bound 27\%). Only 17 of the 27 families were large enough to examine for taxonomic bias in threat status. There was an overall taxonomic bias $\left(\mathrm{X}^{2}=1154.7, \mathrm{df}=17, \mathrm{P}\right.$ b 0.001), with 11 families having a higher status than expected by chance, and two families lower than expected by chance (Table 2).

Criteria for assessment of Threatened species were non-randomly distributed (Fig. 5). As hypothesised, Criterion B (reduction in extent and quality of habitat) was used in the majority of cases, representing $74 \%$ of assessments.

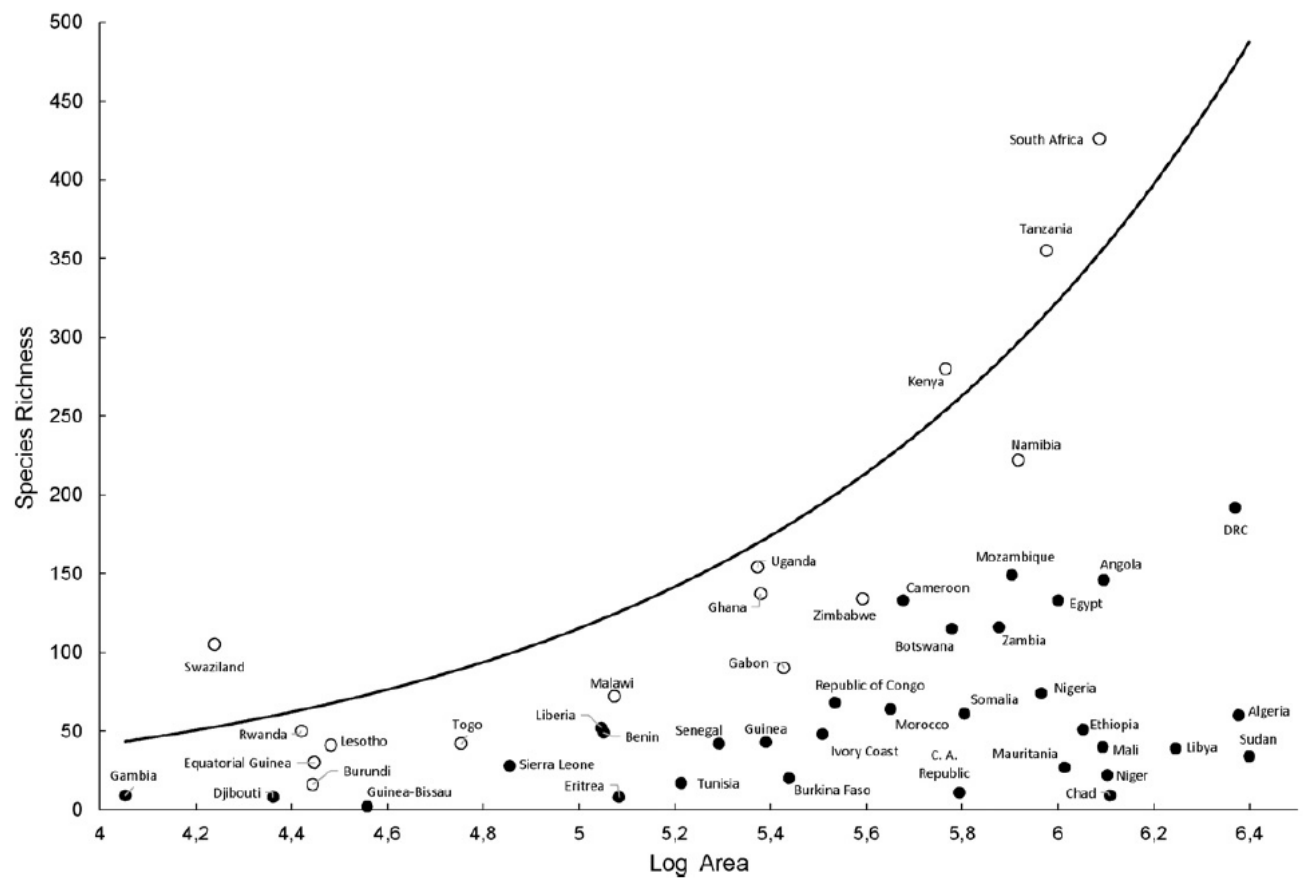

Fig. 3.Scatter-plot showing the measured species richness of reptiles from text descriptions in Uetz and Hošek (2015) relative to log-transformed country area for mainland African countries. Fitted line represents the species-area relationship for 15 best sampled countries only (open circles). 'Sudan' in our analysis refers to the pre-2012 borders.

\begin{tabular}{|c|c|c|c|c|c|c|c|c|c|c|c|}
\hline & EX & $\mathrm{CR}$ & EN & VU & NT & LC & DD & $\mathrm{NE}$ & $\begin{array}{l}\text { \# spp. } \\
\text { assessed }\end{array}$ & $\begin{array}{l}\text { \# spp. } \\
\text { total }\end{array}$ & Threat proportion \\
\hline \multicolumn{12}{|l|}{ a) } \\
\hline Mainland Africa & $2(0.12 \%)$ & $18(1.1 \%)$ & $36(2.2 \%)$ & $52(3.1 \%)$ & $72(4.3 \%)$ & $494(30 \%)$ & $117(15 \%)$ & $85752 \%$ & $791(48 \%)$ & 1648 & $0.077(0.071-0.145)$ \\
\hline Madagascar & $0(0.0 \%)$ & $23(6.0 \%)$ & $51(13.3 \%)$ & $59(15.4 \%)$ & $46(12.0 \%)$ & $157(40.9 \%)$ & $42(10.9 \%)$ & $6(1.6 \%)$ & $378^{*}(98.4 \%)$ & 384 & $0.389(0.346-0.456)$ \\
\hline Total & $3(0.25 \%)$ & $45(3.8 \%)$ & $97(8.1 \%)$ & $100(8.4 \%)$ & $121(10.1 \%)$ & $670(56.2 \%)$ & $156(13.1)$ & $857(74 \%)$ & $1161(52 \%)$ & $2018(48 \%)$ & $0.129(0.119-0.195)$ \\
\hline \multicolumn{12}{|l|}{ b) } \\
\hline Agamids & 0 & $2(5.4 \%)$ & $1(2.7 \%)$ & $3(8.1 \%)$ & $1(2.7 \%)$ & $27(73 \%)$ & 3 (8.1\%) & $40(52 \%)$ & 37 (48\%) & 77 & $0.176(0.162-0.243)$ \\
\hline Amphisbaenians & 0 & $2(6.2 \%)$ & $1(3.1 \%)$ & 3 (9.4\%) & 0 & $12(37 \%)$ & $14(44 \%)$ & 39 (55\%) & $32(45 \%)$ & 71 & $0.333(0.188-0.625)$ \\
\hline Chameleons & 0 & $4(3.9 \%)$ & $14(14 \%)$ & $8(7.9 \%)$ & $19(19 \%)$ & $50(49 \%)$ & $6(5.9 \%)$ & $10(9 \%)$ & $101(91 \%)$ & 111 & $0.274(0.257-0.317)$ \\
\hline Geckos & 0 & $3(1.9 \%)$ & $1(0.7 \%)$ & $12(7.9 \%)$ & $12(7.9 \%)$ & $100(66 \%)$ & $23(15 \%)$ & $158(51 \%)$ & $309(49 \%)$ & 309 & $0.125(0.106-0.258)$ \\
\hline Other lizards & $2(0.9 \%)$ & $2(0.9 \%)$ & $12(5.3 \%)$ & $11(4.9 \%)$ & $29(13 \%)$ & $145(64 \%)$ & $25(11 \%)$ & $233(51 \%)$ & $459(49 \%)$ & 459 & $0.134(0.119-0.230)$ \\
\hline Snakes & 0 & $2(0.9 \%)$ & $7(3.3 \%)$ & 7 (3.3\%) & $10(4.7 \%)$ & $144(67 \%)$ & $44(21 \%)$ & $347(62 \%)$ & $561(38 \%)$ & 561 & $0.094(0.075-0.280)$ \\
\hline Crocodiles & 0 & $1(33 \%)$ & 0 & $1(33 \%)$ & 0 & $1(33 \%)$ & 0 & $1(25 \%)$ & $4(75 \%)$ & 4 & $0.667(0.667-0.667)$ \\
\hline
\end{tabular}


Conversely no species were assessed using criterion $\mathrm{E}$ (quantitative analysis of extinction risk), highlighting the lack of empirical data for African reptiles. Moreover, the underlying threats facing species listed under Criterion B were not evenly distributed (Fig. 5, inset). Agriculture (72\% of species) and resource abstraction (50\% of species) were the major pressures facing Threatened reptiles in Africa. Among species threatened by agriculture we note that 42 species $(75 \%$ of species threatened by agriculture) were directly threatened by non-commercial (i.e. subsistence) agriculture, while commercial agriculture was only implicated in the threat of 19 species ( $34 \%$ of species threatened by agriculture).

Several countries had notably high estimated Threat Index indices, particularly Ethiopia and Burundi, followed by Liberia, Malawi, Rwanda and Sierra Leone (Fig. 5b, Table S1). Botswana had the lowest Threat Index, followed by Gabon, South Africa, Namibia, Morocco and Algeria. In the countries with high Threat Index, distribution data are sparse, and most species have not been through an extinction risk assessment.

\section{Discussion}

The records of African reptiles available from publicly assessable electronic databases are entirely inadequate for assessing patterns of diversity (species richness), which are instead strongly correlated to sampling intensity. The most under-sampled areas include Central, West and the Horn of Africa. Comparatively greater sampling effort has focused on southern and East Africa, but even this is inadequate to realistically define or explain patterns of diversity and richness. This is exacerbated by incomplete taxonomic knowledge, a concern that has been recognised as a global challenge for biodiversity conservation (Pimm et al., 2014). Indeed, the combination of incomplete taxonomic knowledge with the deficit of records creates a particularly risky situation for Africa's reptiles. 


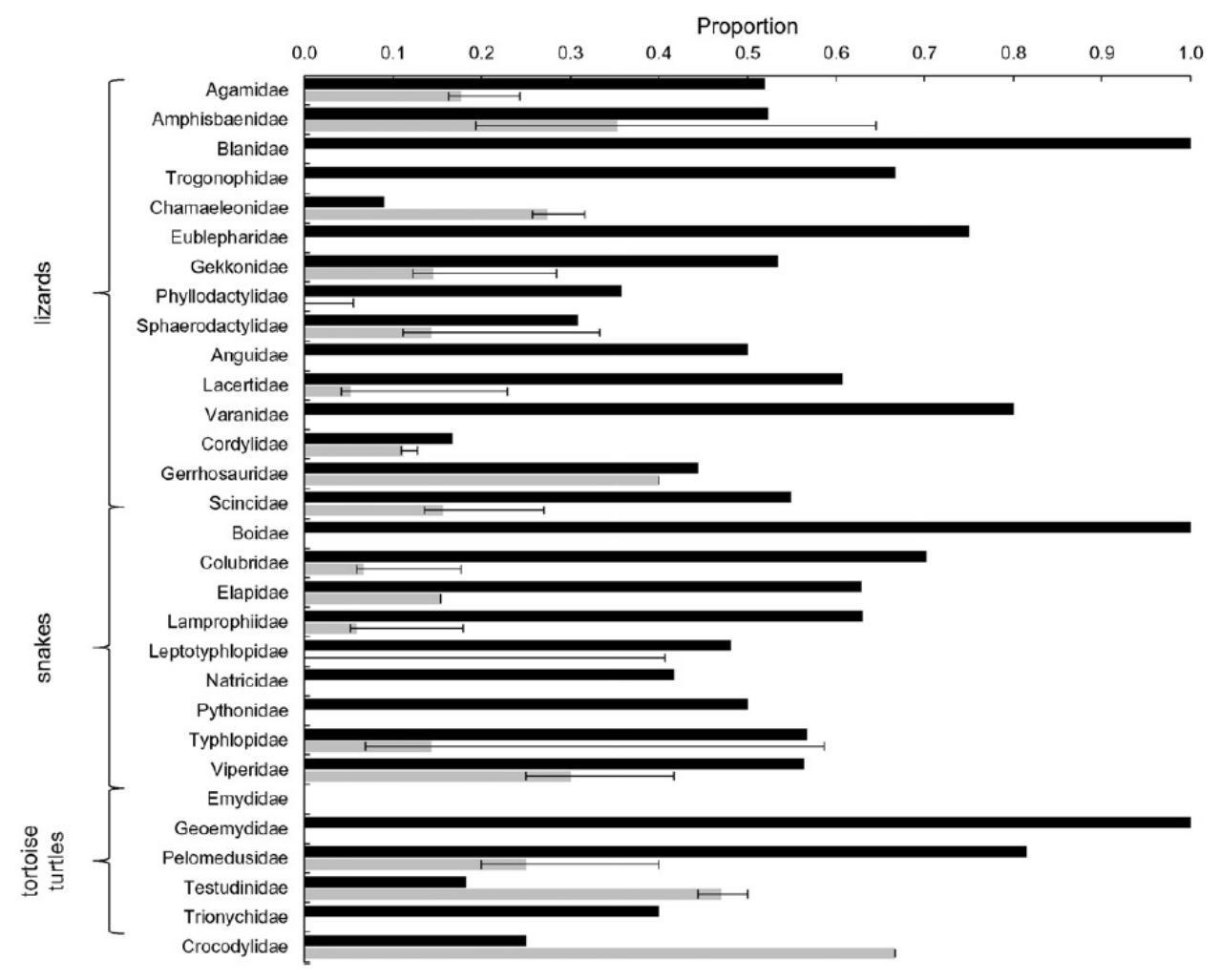

Fig. 4. Extinction risk for mainland African reptiles by family. The dark bar indicates the proportion of species not evaluated (NE), and the light bar indicates the extinction risk by proportion of Threatened species (with upper and lower bounds).

Table 2

Taxonomic bias indicated by the observed and expected distribution of threat for families of African reptiles. Over and under Threatened families are indicated with corresponding P values (ns-not significant). Families excluded from the analysis due to low species numbers are indicated by NA.

\begin{tabular}{|c|c|c|c|c|c|c|}
\hline Family & Proportion observed & Proportion expected & \# non-DD species & Over-threatened P-value & Under-threatened P-value & Under/over threatened \\
\hline Agamidae & 0.176 & 0.047 & 34 & $<0.001$ & ns & Over \\
\hline Amphisbaenidae & 0.353 & 0.040 & 17 & $<0.001$ & ns & Over \\
\hline Trogonophidae & 0.000 & 0.002 & 1 & & & NA \\
\hline Eublepharidae & 0.000 & 0.002 & 1 & & & NA \\
\hline Gekkonidae & 0.146 & 0.161 & 103 & ns & ns & ns \\
\hline Phyllodactylidae & 0.000 & 0.017 & 17 & & & NA \\
\hline Sphaerodactylidae & 0.143 & 0.008 & 7 & $<0.001$ & ns & Over \\
\hline Lacertidae & 0.051 & 0.074 & 39 & ns & ns & ns \\
\hline Varanidae & 0.000 & 0.003 & 1 & & & NA \\
\hline Cordylidae & 0.111 & 0.040 & 54 & $<0.01$ & ns & Over \\
\hline Gerrhosauridae & 0.333 & 0.011 & 9 & $<0.001$ & ns & Over \\
\hline Scincidae $^{*}$ & 0.147 & 0.149 & 95 & ns & ns & ns \\
\hline Colubridae & 0.067 & 0.070 & 30 & ns & ns & ns \\
\hline Elapidae & 0.154 & 0.021 & 13 & $<0.001$ & ns & Over \\
\hline Lamprophiidae* & 0.059 & 0.128 & 68 & ns & $<0.05$ & Under \\
\hline Leptotyphlopidae & 0.000 & 0.031 & 16 & ns & $<0.05$ & Under \\
\hline Pythonidae & 0.000 & 0.002 & 2 & & & NA \\
\hline Typhlopidae & 0.143 & 0.041 & 14 & $<0.001$ & ns & Over \\
\hline Viperidae & 0.300 & 0.033 & 20 & $<0.001$ & ns & Over \\
\hline Emydidae & 0.000 & 0.001 & 1 & & & NA \\
\hline Pelomedusidae & 0.250 & 0.016 & 4 & $<0.001$ & ns & Over \\
\hline Testudinidae & 0.471 & 0.013 & 17 & $<0.001$ & ns & Over \\
\hline Trionychidae & 0.000 & 0.003 & 3 & & & NA \\
\hline Crocodylidae & 0.667 & 0.002 & 3 & $<0.001$ & ns & Over \\
\hline
\end{tabular}

* These families are used sensu lato, and incorporate all subfamilies previously or recently proposed: e . the division of the traditional Scincidae into nine families by Hedges ( 2014 , adopted in part by Uetz and Hošek, 2015), four of which occur in Africa; and the recognition of the African Lamprophiidae, that contains only one Asia genus (Psammodynastes), which was initially proposed as one of six families in the non-elapid Elapoidea (Kelly et al., 2009), all of which have now been subsumed as subfamilies within a greater Lampropiidae (Kelly et al., 2011; Uetz and Hošek, 2015). 
In even the best sampled region (southern Africa), species richness estimated from point locality data corresponds to collecting effort (e.g. Branch, 2014) and as a consequence could result in misdirected conservation efforts (Reddy and Dávalos, 2003). For example, areas around major roads and cities in South Africa are comparatively well sampled (Botts et al., 2011), and these grid cells inaccurately appear in our analysis as having high species richness, a pattern also found in other regions of the globe (e.g. Kadmon et al., 2004; Reddy and Dávalos, 2003). In contrast, most of Central Africa appears to have low species richness, but the region is undeniably under-represented in the data. However, unreliable species richness patterns for African reptiles could potentially be improved through correction methods such as rarefaction or species distribution modelling (Engemann et al., 2015; Gotelli and Colwell, 2001; Jiménez et al., 2009; Mecenero et al., 2015; Raxworthy et al., 2003). Digitisation of distribution maps using field guides and other sources such as IUCN distribution maps has proven useful (Lewin et al., in review; Morales-Castilla et al., 2011), but still cannot account for gaps in information. For example, few records are available for the Congo basin, field guides do not cover this region well, and few Congo basin species have been assessed for IUCN. The result is that studies that compile distribution maps will show the same knowledge gap inherent in the publicly accessible data, and richness patterns will be skewed toward well-known areas that are represented in the sources of the distribution data.

Analysis of the threats reported in conservation assessments for Threatened African reptiles revealed that certain threats are much more prevalent than others (Fig. 5). More than 70\% of the Threatened species are impacted by agriculture, $50 \%$ by resource extraction and approximately $30 \%$ by urbanisation. Similarly, habitat transformation for agriculture was found to be the most prevalent threat for Malagasy reptiles (Jenkins et al., 2014) and for reptiles globally (Böhm et al., 2013, Maritz et al., 2016-in this issue). These primary threats relate chiefly to habitat transformation driven by rapid human population growth. Given that subsistence agriculture is the most important component of the agricultural threat in Africa, that much of the resource extraction in Africa is unregulated, and urbanisation is occurring in Africa at an unprecedented rate (African Economic Outlook, 2014; United Nations, Department of Economic and Social Affairs, Population Division, 2015), the resulting impacts are not easily regulated or controlled. Currently, economic growth in Africa is faster than the global average, and the human population in Africa, already standing at more than a billion, is projected to quadruple over this century (African Economic Outlook, 2014; Gerland et al., 2014). This is likely to result in extreme pressure on natural areas and the lack of strong environmental regulations and enforcement in many areas essentially paves the way for a biodiversity calamity. Africa therefore, should be a priority in terms of biological discovery because the taxonomic diversity must be documented, mapped and assessed if it is to be conserved (Meiri and Chapple, 2016-in this issue). 
Nearly half of mainland Africa's known reptiles have not been assessed for extinction risk, compared to $\sim 60 \%$ globally (Böhm et al., 2013, Meiri and Chapple, 2016-in this issue). Of those assessed, several families are notable for a high percentage of species at risk (Amphisbaenidae, Chamaeleonidae, Gerrhosauridae, Testudinidae, Viperidae), many of which are also disproportionally threatened on the island of Madagascar (e.g. Chamaeleonidae, Gerrhosauridae, Testudinidae; Jenkins et al., 2014). There is a strong overall taxonomic bias in extinction risk with $45 \%$ of families more threatened than expected by chance, which is lower than global estimate of nearly 75\% (Böhm et al., 2013). Many of these taxonomic groups contain habitat specialists (e.g. Amphisbaenidae, chameleons, small vipers) or narrow endemics (e.g. vipers, cordylids) and are threatened under Criterion B (reduction in extent and quality of habitat). The taxonomic bias suggests that some species or families are more vulnerable to threats, which is particularly concerning for taxa that are also evolutionarily distinct (Tonini et al., 2016-in this issue). For example, the widespread conversion of forest for (subsistence) agriculture across Africa is likely to impact forest endemics (i.e. forest dependent chameleons and vipers), than widespread generalists (e.g. lacertids, skinks, agamids). 


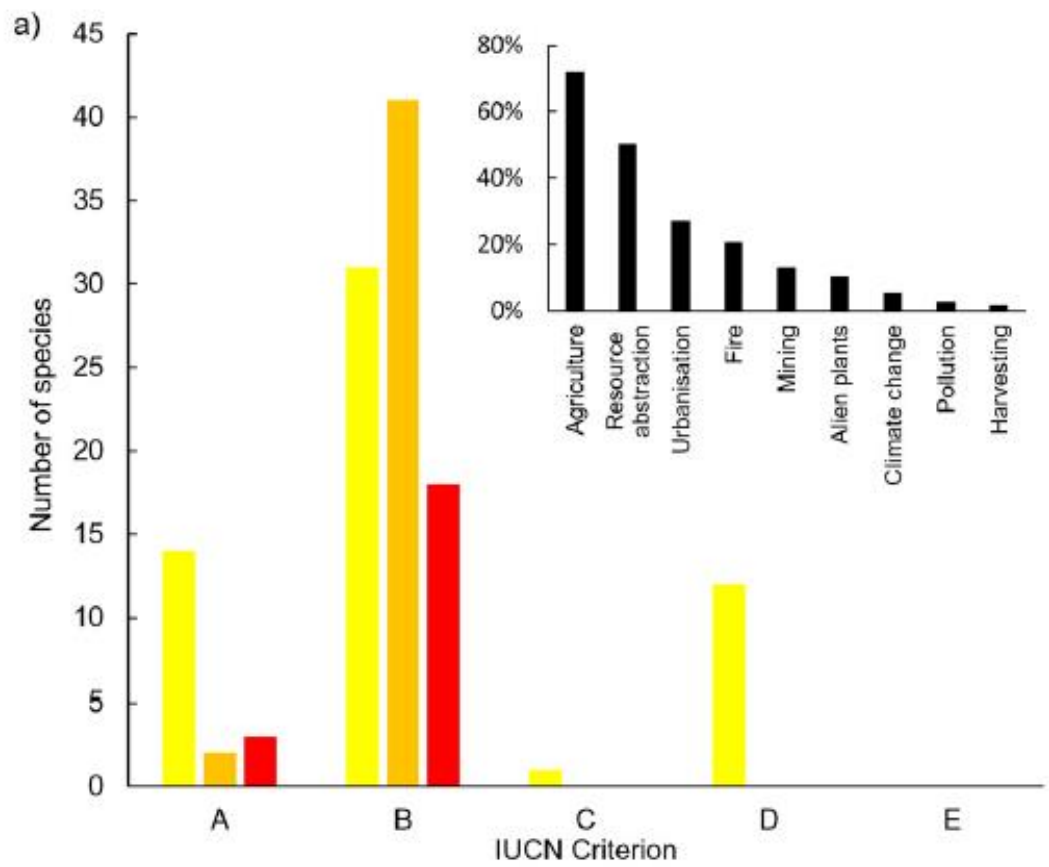

b)

Fig 5. a. The number of mainland African reptiles categorised as threatened under each of the IUCN criteria (red bars, Critically Endangered; orange bars, Endangered; yellow bars, Vulnerable). Inset: Percentage of species listed as threatened under IUCN Criterion B impacted by various threats; $b$. Countrie sof Africa shaded according to Threat Index, with one-degree grid cells where at least one Threatened species occurs. Threat Index is shaded for each country (lightest colour tones indicates low threat status, darker indicate high threat status).

There are a number of countries with a high Threat Index, which are in the same areas that show the most serious data deficiencies (e.g., Ethiopia, Liberia, Rwanda, Sierra Leone). The true impact of the country-level threats is unknown because, due to a lack of information, we are unable to ascertain if these are biodiverse areas. However, even in countries with relatively low Threat Index and relatively good biodiversity information, impacts may be severe. For example, the extinction of Tetradactylus eastwoodae is attributed to habitat loss from afforestation and agriculture in South Africa (Bates et al., 2014), a country with low Threat Index, good knowledge on biodiversity levels and threats (Driver et al., 
2012), and strong biodiversity protection mandated by government (NEMBA, 2004). This begs the question as to what losses have occurred in countries where the fauna is not as well known, risk assessments have not been conducted, and biodiversity protection is not a main concern.

Our accumulated database is certainly not comprehensive with respect to the records that exist for African reptiles. However, it includes most records accessible in public databases - data that can be easily used in conservation planning, environmental impact assessments and any meta-analyses of reptile distribution at a continental scale. Additional data undoubtedly exists in the literature, in museum collections that are not publicly accessible online, and in unpublished or unaccessioned personal datasets. Furthermore, much of the data and specimens collected in Africa are housed in institutions outside Africa, and there has been comparatively little development of collections in Africa. Ultimately, data repatriation to Africa in some form is essential and the development of sustainable, in-country research capacity should be encouraged through collaborations (Böhm and Collen, 2015; Deikumah et al., 2014). In this respect, the development of capacity at African institutions of taxonomic specialists and curation of natural heritage archives (i.e. collections) is essential. This need has been highlighted even for South Africa, which houses two of the three largest herpetological collections on the continent, and yet where taxonomists at museums have declined by $63 \%$ in the last 25 years (Hamer, 2013).

Africa has the majority of the world's low income, low technology countries (African Economic Outlook, 2014; Böhm and Collen, 2015), resulting in few platforms within Africa to curate data and produce research. We propose that the first step to remedy this dire state of affairs would be a concerted effort to centralise existing but inaccessible data in a publicly assessable electronic database such as GBIF (see Böhm and Collen, 2015) to allow African researchers and decisionmakers easy access to data on their biodiversity. This approach should include uploading existing electronic data to public databases, and also mobilising existing data that has not been captured electronically (e.g. historical specimen information). This relatively straightforward and low cost option (as compared to new data collection) could lead to a substantial improvement on the number of publicly accessible records. We caution, however, that such databases need constant maintenance, not only the adjustment of names in line with taxonomic changes, but more importantly in the correct identification of the specimens in collections that are affected by nomenclatural adjustments.

While data mobilisation and centralisation is an important positive step, other actions will certainly be necessary for conservation impacts to be felt. Given the scarcity of financial resources and capacity, efforts should be made for the collection of new information and species discovery in countries with high Threat Index. These areas could also be prioritised for improvement of protection despite 
the lack of good baseline biodiversity data (Polasky, 2008). At present, funding and effort are frequently directed at known biodiversity hotspots but given the problems inherent in hotspot detection, this strategy is likely to simply entrench current biases and result in the need for conservation triage rather than early prevention of losses. Ultimately, habitat transformation is unlikely to abate without substantial improvement on socio-economic and education opportunities in African communities. Closing the biodiversity knowledge gap will be essential for assessing extinction risk (e.g. Bland and Böhm, 2016-in this issue) and planning appropriate actions in light of these growing social challenges.

Supplementary data to this article can be found online at http://dx. doi.org/10.1016/j.biocon.2016.04.006.

\section{Acknowledgements}

We would like to thank the editors of this special issue for the opportunity to contribute, particularly Shai Meiri for providing very useful feedback. We are grateful to Monika Böhm and Ben Collen for use of their R scripts to estimate threat proportion, and Craig Hilton-Taylor for assisting with IUCN data access. Publicly accessible electronic databases were accessed at Global Biodiversity Information Facility, HerpNet, Natural History Museum London, and the Animal Demography Unit at University of Cape Town. 


\section{References}

African Economic Outlook, 2014. African Economic Outlook 2014: global value chains and Africa's industrialisation. African Development Bank, Organisation for Economic Cooperation and Development, United Nations Development Programme, p. 317.

Baha El Din, Sherif, 2006. A Guide to Reptiles \& Amphibians of Egypt. American University in Cairo Press.

Bates, M.F., Branch, W.R., Bauer, A.M., Burger, M., Marais, J., Alexander, G.J., de Villiers, M.S., 2014. Atlas and Red List of the Reptiles of South Africa, Lesotho and Swaziland. South African National Biodiversity Institute, Pretoria.

Bielby, J., Cunningham, A.A., Purvis, A., 2006. Taxonomic selectivity in amphibians: ignorance, geography or biology? Anim. Conserv. 9, 135-143.

Bland, L.M., Böhm, M., 2016. Overcoming Data Deficiency in Reptiles. Biol. Conserv. 204, 16-22 (in this issue).

Böhm, M., Collen, B., 2015. Toward equality of biodiversity knowledge through technology transfer. Conserv. Biol. 29, 1290-1302.

Böhm, M., Collen, B., Baillie, J.E.M., Bowles, P., Chanson, J., Cox, N., Hammerson, G.,

Hoffmann, M., Livingstone, S.R., Ram, M., Rhodin, A.G.J., Stuart, S.N., van Dijk, P.P., Young, B.E., et al., 2013. The conservation status of the world's reptiles. Biol. Conserv. 157, 372-385.

Botts, E.A., Erasmus, B.F.N., Alexander, G.J., 2011. Geographic sampling bias in the South African Frog Atlas Project: implications for conservation planning. Biodivers. Conserv. 20, 119-139.

Branch, W.R., 2014. Conservation status, diversity, endemism, hotspots and threats. In: Bates, M.F., Branch, W.R., Bauer, A.M., Burger, M., Marais, J., Alexander, G.J., de Villiers, M.S. (Eds.), Atlas and Red List of Reptiles of South Africa, Lesotho and Swaziland. South African National Biodiversity Institute, Pretoria, pp. 22-50.

Chapman, A.D., 2009. Numbers of Living Species in Australia and the World. Report for the Australian Biological Resources Study, second ed. Canberra.

Chiarucci, A., Bacaro, G., Scheiner, S.M., 2011. Old and new challenges in using species diversity for assessing biodiversity. Philos. T. Roy. Soc. Lond. 366, $2426-2437$.

Davies, T.J., Buckley, L.B., 2011. Phylogenetic diversity as a window into the evolutionary and biogeographic histories of present-day richness gradients for mammals. Philos. T. Roy. Soc. Lond. 366, 2414-2425.

Deikumah, J.P., McAlpine, C.A., Maron, M., 2014. Biogeographical and Taxonomic Biases in Tropical Forest Fragmentation Research. Conserv. Biol. 28, 1522-1531.

Driver, A., Sink, K.J., Nel, J.N., Holness, S., Van Niekerk, L., Daniels, F., Jonas, Z., Majiedt, P.A., Harris, L., Maze, K., 2012. National Biodiversity Assessment 
2011: an assessment of South Africa's biodiversity and ecosystems. Synthesis Report. South African National Biodiversity Institute and Department of Environmental Affairs, Pretoria.

Engemann, K., Enquist, B.J., Sandel, B., Boyle, B., Jørgensen, P.M., MoruetaHolme, N., Peet, R.K., Violle, C., Svenning, J.-C., 2015. Limited sampling hampers "big data" estimation of species richness in a tropical biodiversity hotspot. Ecol. Evol. 5, 807-820.

Fleishman, E., Noss, R.F., Noon, B.R., 2006. Utility and limitations of species richness metrics for conservation planning. Ecol. Indic. 6, 543-553.

Forest, F., Grenyer, R., Rouget, M., Davies, T.J., Cowling, R.M., Faith, D.P., Balmford, A., Manning, J.C., Proches, S., van der Bank, M., Reeves, G., Hedderson, T.A.J., Salvolainen, V., 2007. Preserving the evolutionary potential of floras in biodiversity hotspots. Nature 445, 757-760.

Gerland, P., Raftery, A.E., Ševčíková, H., Li, N., Gu, D., Spoorenberg, T., Alkema, L., Fosdick, B.K., Chunn, J., Lalic, N., Bay, G., Buettner, T., Heilig, G.K., Wilmoth, J., 2014. World population stabilization unlikely this century. Science 346, 234-237.

Gotelli, N.J., Colwell, R.K., 2001. Quantifying biodiversity: procedures and pitfalls in the measurement and comparison of species richness. Ecol. Lett. 4, 379-391.

Hamer, M., 2013. A National Strategy for Zoological Taxonomy (2013-2020). South African National Biodiversity Institute, Pretoria Unpublished report.

Hedges, S.B., 2014. The high-level classification of skinks (Reptilia, Squamata, Scincomorpha). Zootaxa 3765, 317-338.

Hoffmann, M., Hilton-Taylor, C., Angulo, A., Böhm, M., Brooks, T.M., Butchart, S.H.M., Carpenter, K.E., Chanson, J., Collen, B., Cox, N.A., et al., 2010. The impact of conservation on the status of the world's vertebrates. Science $330,1503-1509$.

IUCN, 2015. The IUCN Red List of Threatened Species. Version 2015.1. bhttp://www. iucnredlist.orgN. Downloaded on O1 June 2015.

Jenkins, C.N., Pimm, S.L., Joppa, L.N., 2013. Global patterns of terrestrial vertebrate diversity and conservation. P. Natl. Acad. Sci. USA 110, E2602E2610.

Jenkins, R.K.B., Tognelli, M.F., Bowles, P., Cox, N., Brown, J.L., Chan, L., Andreone, F., Andriamazava, A., Andriantsimanarilafy, R.R., Anjeriniaina, M., et al., 2014. Extinction risks and the conservation of Madagascar's reptiles. PLoS One 9, e100173.

Jenkins, C.N., Van Houtan, K.S., Pimm, S.L., Sexton, J.O., 2015. US protected lands mismatch biodiversity priorities. P. Natl. Acad. Sci. USA 112, 5081-5086.

Jiménez, I., Distler, T., Jørgensen, P.M., 2009. Estimated plant richness pattern across northwest South America provides similar support for the species-energy and spatial heterogeneity hypotheses. Ecography 32, 433-448. 
Kadmon, R., Farber, O., Danin, A., 2004. Effect of roadside bias on the accuracy of predictive maps produced by bioclimatic models. Ecol. Appl. 14, 401413 .

Kelly, C.M.R., Barker, N.P., Villet, M.H., Broadley, D.G., 2009. Phylogeny, biogeography and classification of the snake superfamily Elapoidea: a rapid radiation in the late Eocene. Cladistics 25, 38-63.

Kelly, C.M.R., Branch, W.R., Broadley, D.C., Barker, N.P., Villet, M.H., 2011. Molecular systematics of the African snake family Lamprophiidae Fitzinger, 1843 (Serpentes: Elapoidea), with particular focus on the genera Lamprophis Fitzinger 1843 and Mehelya Csiki 1903. Mol. Phylogenet. Evol. 58, 415-426.

Laffan, S.W., Lubarsky, E., Rosauer, D.F., 2010. Biodiverse, a tool for the spatial analysis of biological and related diversity. Ecography 33, 643-647.

Lewin, A., Feldman, A., Bauer, A.M., Belmaker, J., Broadley, D.G., Chirio, L., Itescu, Y., LeBreton, M., Maza, E., Meirte, D., Nagy, Z.T., Novosolov, M., Roll, U., Tallowin, O.,

Trape, J.-F., Vidan, E., Meiri, S., 2016. Drivers of reptile species richness in Africa. J. Biogeogr. (in review).

Luiselli, L., 2008. Community ecology of African reptiles: historical perspective and a meta-analysis using null models. Afr. J. Ecol. 46, 384-394.

Maritz, B., Penner, J., Martins, M., Crnobrnja-Isailović, J., Spear, S., Alencar, L.R., Sigala

Rodriquez, J., Messenger, K., Clark, R.W., Soorae, P., Luiselli, L., Jenkins, C., Greene, H.W., 2016. Identifying Global Priorities for the Conservation of Vipers. Biol. Conserv. 204, 94-102 (in this issue).

Mecenero, S., Altwegg, R., Colville, J.F., Beale, C.M., 2015. Roles of spatial scale and rarity on the relationship between butterfly species richness and human density in South Africa. PLoS One 10, e0124327.

Meiri, S., Chapple, D.G., 2016. Biases in The Current Knowledge of Threat Status in Lizards, and Bridging the 'Assessment Gap'. Biol. Conserv. 204, 6-15 (in this issue).

Mittermeier, R.A., Robles Gil, P., Hoffman, M., Pilgrim, J., Brooks, T., Goettsch Mittermeier, C., Lamoreux, J., da Fonseca, G.A.B., 2004. Hotspots Revisited. CEMEX, Agrupación Sierra Madre, S.C., Mexico City.

Morales-Castilla, I., Olalla-Tarraga, M.A., Bini, L.M., De Marco, P., Hawkins, B.A., Rodriguez, M.A., 2011. Niche conservatism and species richness patterns of squamate reptiles in eastern and southern Africa. Austral Ecol. 36, 550558.

Murdoch, W., Polasky, S., Wilson, K.A., Possingham, H.P., Kareiva, P., Shaw, R., 2007. Maximizing return on investment in conservation. Biol. Conserv. 139, 375-388.

Myers, N., Mittermeier, R.A., Mittermeier, C.G., Da Fonseca, G.A.B., Kent, J., 2000. Biodiversity hotspots for conservation priorities. Nature 403, 853858. 
NEMBA, 2004. No. 10 of 2004: National Environmental Management: Biodiversity Act, 2004, No. 26436. Government Gazette, Republic of South Africa.

Petchey, O.L., Gaston, K.J., 2002. Functional diversity (FD), species richness and community composition. Ecol. Lett. 5, 402-411.

Pimm, S.L., Jenkins, C.N., Abell, R., Brooks, T.M., Gittleman, J.L., Joppa, L.N., Raven, P.H.,

Roberts, C.M., Sexton, J.O., 2014. The biodiversity of species and their rates of extinction, distribution, and protection. Science 344, 1246752.

Polasky, S., 2008. Why conservation planning needs socioeconomic data. P. Natl. Acad. Sci. USA 105, 6505-6506.

R Development Core Team, 2011. R: A Language and Environment for Statistical Computing. The R Foundation for Statistical Computing, Vienna, Austria.

Raxworthy, C.J., Martinez-Meyer, E., Horning, N., Nussbaum, R.A., Schneider, G.E., Ortega-Huerta, M.A., Townsend Peterson, A., 2003. Predicting distributions of known and unknown reptile species in Madagascar. Nature 426, 837-841.

Reddy, S., Dávalos, L.M., 2003. Geographical sampling bias and its implications for conservation priorities in Africa. J. Biogeogr. 30, 1719-1727.

Scott, J.M., Csuti, B., Jacobi, J.D., Estes, J.E., 1987. Species richness. Bioscience 37, 782-788. Tonini, J.F.R., Beard, K.H., Ferreira, R.B., Jetz, W., Pyron, R.A., 2016. Fully-sampled phylogenies of squamates reveal evolutionary patterns in current extinction risk. Biol. Conserv. 204, 23-31 (in this issue).

Uetz, P., Hošek, J., 2015. The Reptile Database. http://www.reptile-database.org accessed 1 June 2015 .

United Nations, Department of Economic and Social Affairs, Population Division, 2015,. World Population Prospects: The 2015 Revision, Key Findings and Advance Tables Working Paper No. ESA/P/WP.241.

Wilson, L.D., Mata-Silva, V., Johnson, J.D., 2013. A conservation reassessment of the reptiles of Mexico based on the EVS measure. Amphibia-Reptilia 7, 147. 